\title{
Why Do We Need a New Librarianship?
}

\author{
R. David Lankes \\ University of South Carolina
}

\begin{abstract}
A Library is not just an information distributing machine and reading not its steam as the paradigm of the industrial age has seen it. Even the conception of the Library as Information Agency established in the 20th century does not meet any more the needs of our communities. In the age of data'ism the Library is not about Information as a thing and neutral IT infrastructures. It needs a more critical world view. Instead of data and information a new library science should focus on knowledge and knowing. The communities library serve are the true collections; librarians the weavers of community narratives and understandings.
\end{abstract}

Keywords: New librarianship; DIKW; information age; knowledge; community; conversation theory; participation; learning

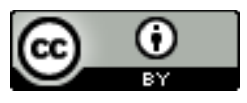

This is an Open Access article distributed under the terms of the Creative Commons Attribution 4.0 International License (http://creativecommons.org/licenses/by/4.0), which permits unrestricted use, distribution, and reproduction in any medium, provided the original work is properly cited. 


\section{Industrial Age Librarianship}

During the United States of America's Centennial celebration in Philadelphia in 1876103

librarians (90 men and 13 women) gathered for a "Convention of Librarians" (American Library Association, 2019). It was this meeting that is often cited as the beginning of the American Library Association. The event was organized by well-known names in librarianship to this day: Dewey, Cutter, and Bowker, etc. It was seen as part of a move of librarianship in the states "from a vocation to a modern profession" (OCLC, 2019).

Melvil Dewey, in particular, is given credit (often uncritically) for shaping modern day librarianship. With the creation of the first library school, wide distribution (and advocacy for) universal methods of classification, and an ongoing role in professional societies Dewey played a strong role in the foundations of librarianship as we know it globally. An emphasis on standardization, removing duplicative work, and a general focus on "libraries" versus local concepts of "the library," Dewey and his cohort forged a view of librarianship we can still recognize today.

However, these events of late $19^{\text {th }}$ century librarianship are very much products of the age in which they were formulated. Universal classification, standardized service definitions, even the concept of a library worker were formed in the heart of the industrial age. A drive to efficiency and costeffectiveness still permeates nearly every part of the operation of libraries. Copy cataloging, a push to consortia, inter-library loan, even more recent moves in library science education, can be seen as preparing people to work in a sort of "knowledge factory." Take Dewey’s quotes like:

"A library's function is to give the public in the quickest and cheapest way information, inspiration, and recreation. If a better way than the book can be found, we should use it" (Goodreads, 2019), or 
"Reading is a mighty engine, beside which steam and electricity sink into insignificance" (Goodreads, 2019).

Many may read these as inspirational messages around reading and books, but pay attention to the metaphors. The future of libraries, public and academic, was in scale and the lessons learned on the assembly line. Note the phases "quickest and cheapest," and the analogy of reading to steam.

This is no big revelation. Today we too adopt the trappings and concepts of the society around us: information as power, networks as engines of democracy. Invisible colleges of scholars have become webs and social networks. The point is that as society evolves and faces new challenges the way we think and act are deeply influenced by our inventions and the constructs we create to cope with the dynamics of a "new" world.

Yuval Harari, the historian, in his book Sapiens (2015) lays out a compelling case for the evolution of humanity and the emergence of human society through our ability to construct and believe in social constructs. According to Harari everything from money, to religion, to nations, to democracy are results of a cognitive revolution that allows our species to interact on a global scale with literally billions of others. These changes are not universally positive, and indeed are rarely cleanly divided into positive or negative. While capitalism has driven growth and a higher standard of living, for example, it has also led to massive inequities and exploitation of labor.

Indeed, even attributing positive attributes to social constructs can shift through time. Few today would stand to defend global colonialism. Fewer still would stand to label Dewey as the father of modern librarianship without also pointing out his strong antisemitism or misogyny. Our profession, being intimately tied to society and humanistic endeavors such as learning and knowledge development, are strongly influenced by the evolution of social constructs. They must be in order to remain relevant. The short answer to the question in the title of this piece is simple: we need a new Journal of New Librarianship, 4 (2019) pp. 314-327 10.21173/newlibs/7/3 
library science to better serve our communities because older conceptions of the field no longer meet up to today's worldview ${ }^{1}$.

\section{From Ages of Industry to Information}

We saw this shift at the turn of the $20^{\text {th }}$ century when librarianship was recast in industrial terms. More recently we have seen this shift with the adoption of "information" at the core work of librarianship in the 80s and 90s. Readers and patrons became users. Instead of talking about books and volumes we moved to documents and resources. Libraries went from places of quiet reading to information access points - the size of our collection now defined in licensed resources over purchased volumes.

For many today, this information worldview is nearly invisible. The social construct many librarians function within are so dominant and tied into society, they become difficult to see. Yet, just as early library advocates embedded their concepts into the profession, we do as well.

It should also be noted that this information worldview was more than simply how we labeled things. Over the past 50 years seismic changes have transformed libraries. Collections not only shifted from primarily analog to increasingly digital, but from primarily owned resources to primarily licensed ones. The collection itself transformed from a single cohesive thing to a hybrid concept where distributed repositories are joined through metadata and discovery systems. Today library collections are on the shelves, in the archives, and more and more in the cloud. In a very real way even the smallest library includes the resources of the internet in their offerings.

\footnotetext{
${ }^{1}$ For more on Worldview see pages 15-23 in Lankes, R. D. (2011). The atlas of new librarianship. Cambridge, MIT Press.
} 
Public services have changed as well. Reference librarians that were once portrayed as oracles with massive memories of facts and figures are now finders of resources. Reference itself, once an alternative interface to a collection, is becoming a collaboration and instructional activity.

There simply wasn't room in an industrial model for what we now think of as information services. What is local? What is findable? What "distributed" meant in the $19^{\text {th }}$ century is fundamentally different than "distributed" in the $20^{\text {th }}$. And so, a new worldview with its own "library science" was created and adopted.

It is now time to rethink library science once again because the information paradigm is simply stretching beyond its bounds, and no longer matches the reality of our communities. For example, the information worldview lacks the increasingly obvious need to represent cultural power dynamics and the intricate ambiguities of how people make meaning. The information field, with its origins in the 1940s (Shannon, 1948), sees information as a thing - a resource to be consumed, transmitted, processed, and stored. It is why patrons have become users and users are becoming customers or clients. The library discipline has adopted many of the consumer/producer dichotomies evident in the corporate sector.

This adoption of information technology and concepts of information management have repercussions for librarianship. Information and the systems used to manipulate it are often seen as neutral - technology as thing. Yet, with the advances in technology we are seeing more and more how algorithms are actually embedded perspectives, biases, and outright discrimination (Knight, 2017). Issues central to librarianship such as privacy, diversity, and transparency are often skewed or simply absent from an industry perspective of information.

In an information worldview, libraries too rarely challenge these technological trade-offs, but rather seek to emulate the ease of use of search engines. In an information world, we too often Journal of New Librarianship, 4 (2019) pp. 314-327 10.21173/newlibs/7/3 
scramble to Facebook for likes and Twitter for followers. In too many cases we have transformed advocating for the well-being of our communities into designing user experiences.

Let me be clear that I am not making some blanket statement that all corporate driven services are antithetical to librarianship. I am also not calling for some sort of neo-luddite'ism where librarians shun technology and return to books and Dewey's reading as steam. What I am calling for is a new worldview that prepares our communities to critically challenge the world around them, move beyond use and even outdated concepts of institutions, and re-focus on how people - not users or customers or patrons - make meaning in their lives. I am calling for a new - or more accurately - renewed librarianship.

\section{A New Librarianship}

Not all parts of a new librarianship will indeed be "new." There are some very old ideas that are embraced. In some cases, brilliant and radical ideas that have either become lost, or so widely adopted that we have forgotten they were once radical. The call is not to discard the past, but to reexamine the field and ensure it meets the needs and social constructs of today.

I argue that this new librarianship is founded on concepts of knowledge and learning instead of data and information (Lankes, 2011). Further that knowledge is inherently human-centered. That is, how a person understands and reacts to the world is knowledge. Knowledge cannot be copied, bound, or even truly distributed. Knowledge creation, or more simply, learning, is how people process data and information cognitively and in a social context. This is hardly new.

What is new, is that when you focus on something inherently human, you naturally focus on people and how they make meaning. Not focusing on how people use a system (like a phone or a 
library) or how people consume information/documents/books/games. In essence librarianship is focused on how people create.

The ultimate problem with an information approach is that it flattens the views of our communities and those we seek to serve to algorithms and processors, not people and aspirations. Information providers have users that take in data, process it, and enact behavior (Harari, 2017).

If that sounds too foreign or sterile, ask yourself how comfortable you are with the idea that libraries provide materials to enrich a love of reading? Libraries provide the essential information for citizens of a democracy to make informed votes? Businesses need access to the latest data to improve their bottom line. All of those statements are in the form of data into a process to an action. Great sounding calls to action around intellectual freedom too often talk about opportunity in the market and too little about what it means to be human and have access to knowledge.

It can be hard to see because we live inside this narrative every day in every corner of our lives. We too often have accepted the role of libraries as an answer to access instead of an agent of impact. The narrative is so powerful that we no longer see the difference. Access to information equals positive impact in people's lives.

But I need to step back. I am using terms that have yet to be defined. I will use the definitions of data, information, and most importantly, knowledge and knowing, that will help highlight the current trends and possible ways forward.

- Data are discrete objective facts; or raw measurements and observations, which are unorganized, unprocessed, and do not convey any specific meaning

- Information is the organization and/or processing of data into meaningful patterns

- Knowledge consists of the beliefs, attitudes, experiences, and structures that exist in the mind (subconscious and conscious) and influence behavior 
- Knowing is the conscious application of knowledge

There is probably nothing in here that surprises you. It initially appears to be a form of the Data, Information, Knowledge, Wisdom Hierarchy (Wikipedia, 2019). However, the one thing, before we go any further, that we must acknowledge is that all of these terms are defined from the perspective of the individual. That is, what is data, knowledge and so on is ultimately defined by a person in a given context. What I see as data, you may not. What I see as knowledge, you may not.

Why is that important? Because for too long librarians have been focused on the wrong thing. Either we have confused things like books, documents, images, articles, and so on with knowledge, or we have seen information as somehow objective and universal.

\section{On Impact, Information, and Knowledge}

Picking up on my earlier point that we confuse access for impact, that is really a confusion with information with knowledge. In the information narrative that pervades our profession we see providing someone with access to information as our job - because we assume that information is power. If we want greater literacy in rural areas, we build a library, or even better, lay some fiber, and that community has access to information. Now they can learn and get better... a term we never seem to define beyond: "have better access."

So, what if the materials in that library don't reflect the experiences, cultures, or values of that distant community - information is information. Let's ship boats full of books to sub-Saharan Africa when what they need is access to biomedical research trapped behind pay walls. Or let's ship books to the tribal lands instead of providing a platform for their stories to reach the rest of the world.

The author Chimamanda Adichie (2009) talks about the power of fiction. She talks about how so often the stories of African nations are reduced to war, poverty, and need that soon that is all those 
in the west see. She argues, what is needed, are stories. Stories of girls coming of age in Uganda, or fathers raising children in Rwanda - we need stories of real life and images of the ordinary so we can connect to Africans as people. So that we can know the peoples of Africa, not simply "be informed."

Because at the end of the day librarians job is not to inform a community. It is not to provide access to a community. It is to improve a community. A community of scholars, or a city, or a school should be better because of the work of a librarian.

But what is better? Isn't more informed or more connected better? Isn't the ability to access and analyze more data faster better? That's what a data and information narrative would tell us. Yet, what happens if instead of taking those things for granted, we question.

\section{The Information Literacy Example}

For example, take the concept of information literacy. In an information/data narrative information literacy is the ability to better process information. By gaining greater sophistication in how we evaluate information sources we can make better decisions goes the logic. Except that it doesn't work. Humans keep getting in the way.

Study after study show that if you ask a group how good are they at seeking out information, then run them through expert instruction of information seeking and selection, at the end that group will tell you they are now better...but analysis of their actual performance is unchanged. That's right, for a lot of information literacy work, we are making people feel more confident about poor skills.

But it gets worse. Psychology study after psychology study show us that if someone holds an erroneous idea, presenting that person evidence of the error only leads them to have a stronger belief in the error! Unless, and here's the important part, you can get them to acknowledge their ignorance first. 
The irony of information literacy, indeed all of education, is that to make someone smarter, you must first get them to accept how ignorant they are. This is true of not just individuals, but groups, communities, and societies. No one in the dark ages thought of themselves as ignorant. No one in 12th century Europe walked around saying "if only I knew more, my life would be better," because they thought all that was to be known, was known.

Either it had been discovered in the glories of Rome or it was encoded in the Bible. How to live a good life, how to grow trees, why people die - it was known. It was not until a society first acknowledged that knowing more about botany, physics, chemistry, and anatomy could lead to discovery and a better life that they could extend our life spans, build new machines, and eventually fly to the moon. In order to advance in the possibilities of knowledge, they first had to admit there was much they didn't know - they had to embrace their ignorance.

Think about how this changed the work librarians do today. Instead of seeing a library as a container of all the knowledge there is - a library became a place to discover new knowledge. Monastic and academic libraries that once held the truth, became college, public, and school libraries that helped scholars and students and citizens invent and grow.

\section{From Information to Data or Knowledge?}

It is tempting to see the emerging data'ism (Harari, 2017) and information as an extension of this movement. After all we can now mine data for discovery. Information and information technology seem like new liberators that link people in discovery. However, this is where a new librarianship must keep a critical eye, because the danger we must avoid, and I think the one of the central purposes of the field of information and library science, is to not look to data stores and algorithms as the new holy texts that hold all the answers. 
To be sure, massive scale computing and the explosion in data generating devices have brought fantastic benefits to our lives. Google allows us to search across trillions of webpages in milliseconds. Wikipedia allows us as a global society to build an open repository of ideas, histories, and concepts. Embedded medical devices can allow patients and doctors to monitor and maintain health anywhere in the world. A new librarianship does not dismiss these advances.

Instead we must ask is an information perspective sufficient to guide librarianship now and into the future? Is information and or data sufficient for creating knowledge and finding meaning? The answer there is clearly no. We've already talked about the annoying ability of human beings to ignore evidence that they disagree with, but we can go farther. Take the 2016 US Presidential election. All of the major media polling data showed one result, that was wrong. Was it wrong because the pollsters didn't know how to do statistics? No, in fact the statistics were extremely complex and had proven successful for over a decade. Was it because there was too little data? Absolutely not. There was enormous time and money spent to get “representative” samples. Was it because the polls weren't believed? Absolutely not, in fact the reporting and media narratives seemed to corroborate the finding of the polls. Then why was it wrong? Simple answer - people. The people who ran the polls started with assumptions of who to talk to, who tells the truth, and how people vote based on demographics. The data collected ultimately reflected more about the people who made the polls, than the people they polled.

We have come to assume that more data brings us closer to reality, and that data are neutral. The truth is that data are collected at the direction of people who are biased and working on a shared worldview. Moreover, just as too little data can provide a skewed view of the world, too much data can lose nuance and distinction in a complex reality. 
Simply put, data and information as a foundation for today's librarianship is insufficient. Library science must move onto a discipline based upon knowledge.

\section{Knowledge Shaped Librarianship}

In a new embrace of knowledge as a central driving force in librarianship, librarians build an engaged relationship with our communities and facilitate a conversation around the hopes and aspirations of that community. Too often we focus on deficiencies - who can't read, who needs economic development, who is college ready? Our data is great at showing us what we are not. We need to know what the narrative of the community is. Do we - the community and the librarian together- want to be an outstanding research university? Do we want to be a literate town, or an engine of economic development, or simply the place with the best quality of life? And no algorithm can define with nuance and passion, ideas like "quality of life."

To do this is not a simple matter of staffing a building waiting for questions and community. Knowledge is all about learning and that is participatory. It requires us to be in the community, proactively seeking conversations. Reference librarians must be in the classroom, and the lab, and the halls of commerce. Not there to advertise libraries, but to listen to the conversation, participate when we can, but always look to link conversations and communities together.

Cataloging and acquisition needs to be more about knowing what people are trying to learn, than what materials are available. Yes, we can use data such as circulation statistics and holds to do that, but more powerful is sitting with community members and asking them what they are passionate about, and to tell their stories. Every library should have production facilities to capture oral histories, publish the work of the community, and stream out podcasts of community voices. Remember, 
knowledge is not about consumption, it is about making meaning, and that comes from conversation. Can I go to your library and hear the voices of your people?

\section{A New Library Science}

This shift from industrial scale provision of materials to information to knowledge requires a new approach to the study of librarians and library service. A beginning to this approach can be seen in this issue. A knowledge focus - what has been referred to as the knowledge school of thought in librarianship-necessitates the use theory of learning. In particular constructivist (Talja, Tuominen, \& Savolainen, 2005) concepts of learning. My own work builds on Gordon Pask's Conversation theory (Pask, 1976) and newer dialectic conceptual frameworks to seek to understand how people build knowledge in a social framework. It is founded on the theory that knowledge construction is a cognitive process shaped by a dynamic social environment.

To truly study libraries, or more precisely librarians and their interactions with communities served, focus needs to be put on learning. It also needs to determine better metrics for participation over use. In other words, we need a library science that understands making meaning is not simply need plus exposure, but a complex interaction of the individual and the community together. We must build on the work of user experience and design thinking to provide platforms for individuals to encounter, understand, and then incorporate materials and thoughts into their own knowledge. The interfaces and systems designed in library science must go beyond modeling people as users that define them only in relation to a system they use. Discovery systems must facilitate searching and direct task integration. Our library systems must shed attempts at universal ways of organizing and presenting documents, and instead focus on capturing and exploiting unique relationships a person makes between documents, ideas, and people. Ontological work, such as FRBR, 
needs to understand that the determination of things likes works, and instances are definitions of the individuals more so than the materials being described. For libraries to fully embrace semantic web, they must see that semantics is a field about meaning, and that meaning is individual and a constant negotiation between individuals' knowledge and the social context they find themselves within.

Lastly, shifting to knowledge makes the study of community, cognition, and learning central to library science over user-system interactions and material organization.

\section{Conclusion}

Ultimately, we do not have users or customers or patrons. We have people seeking to make meaning in their lives. They do that by reading AND writing. They do that by watching AND sharing AND creating. As librarians who adopt a new librarianship, you are now a corps of community engagement activists. Your job is not about materials or buildings...those are tools. Your job is about people, with your community being your true collection. You are not gatekeepers, but rather weavers of community narratives and understandings. You must be brave in bringing together the discordant voices of our members, bold in reaching out of your comfort zone to make those around you comfortable in sharing and learning. This is our time, we are the right profession, and our communities need us. Let's get started. 


\section{References}

Adichie, C. N. (2009). The danger of a single story. TED Talk Retrieved September 12, 2019 from: https://www.youtube.com/watch?v=D9Ihs241zeg

American Library Association (2019). History. Retrieved September 12, 2019 from:

http://www.ala.org/aboutala/history

Goodreads (2019). Melvil Dewey - Quotes. Retrieved September 12, 2019 from:

https://www.goodreads.com/author/quotes/42741.Melvil_Dewey

Harari, Y. N. (2015). Sapiens: A brief history of humankind. London: Vintage.

Harari, Y. N. (2017). Homo Deus. London: Harper.

Knight, W. (2017, July 12). Biased algorithms are everywhere, and no one seems to care. MIT

Technology Review. https://www.technologyreview.com/s/608248/biased-algorithms-areeverywhere-and-no-one-seems-to-care/

Lankes, R. D. (2011). The atlas of new librarianship. Cambridge, MA: MIT Press.

OCLC (2019). How one library pioneer profoundly influenced modern librarianship. Retrieved September 12, 2019 from: https://www.oclc.org/en/dewey/resources/biography.html

Pask, G. (1976). Conversation theory: Applications in education and epistemology. New York: Elsevier. Shannon, C.E. (1948, July). A mathematical theory of communication. Bell System Technical Journal, $27(3), 379-423$.

Talja, S., Tuominen, K., \& Savolainen, R. (2005). "Isms" in information science: constructivism, collectivism and constructionism. Journal of Documentation, 61 (1), 79-101.

Wikipedia (2019). DIKW pyramid. Retrieved September 12, 2019 from:

https://en.wikipedia.org/wiki/DIKW_pyramid

Journal of New Librarianship, 4(2019) pp. 314-327 10.21173/newlibs/7/3 